\title{
İmmün Sistemi Baskılanmış Pnömonili Hastalarda Pneumocystis jirovecii Enfeksiyon ve Kolonizasyonlarının Araştırılması
}

\section{Investigation of Pneumocystis jirovecii Infection and Colonization in Immunocompromised Patients with Pneumonia}

\author{
Harun GÜLBUDAK ${ }^{1}(I D)$, Candan ÖZTÜRK$^{1}(I D)$, Sibel KUYUGÖZ²(ID), Seda TEZCAN ÜLGER ${ }^{1}(I D)$ \\ ${ }^{1}$ Mersin Üniversitesi Tıp Fakültesi, Tıbbi Mikrobiyoloji Anabilim Dalı, Mersin. \\ ${ }^{1}$ Mersin University Faculty of Medicine, Department of Medical Microbiology, Mersin, Turkey. \\ ${ }^{2}$ Mersin Üniversitesi Tıp Fakültesi, Enfeksiyon Hastalıkları ve Klinik Mikrobiyoloji Anabilim Dalı, Mersin. \\ ${ }^{2}$ Mersin University Faculty of Medicine, Department of Infectious Diseases and Clinical Microbiology, Mersin, Turkey.
}

* Bu çalış̧ma, Mersin Üniversitesi Bilimsel Araştırma Birimi tarafından 2017-1-TP3-2262 numaralı proje ile desteklenmiş olup Mersin Üniversitesi Tıp Fakültesi, Tıbbi Mikrobiyoloji Anabilim Dalında doktora tezi olarak hazırlanan çalısmanın bir bölümünü oluşturmaktadır.

Makale Atıfı: Gülbudak H, Öztürk C, Kuyugöz S, Tezcan Ülger S. Immün sistemi baskılanmış pnömonili hastalarda Pneumocystis jirovecii enfeksiyon ve kolonizasyonlarının araştırılması. Mikrobiyol Bul 2020;54(4):583-595.

\section{ÖZ}

Pneumocystis jirovecii, immün sistemi baskılanmış hastalarda P.jirovecii pnömonisi (PCP)'ne neden olan atipik bir fungustur. Günümüzde, AIDS ilişkili PCP insidansı azalırken, immün sistemi baskılayıcı tedavi gerektiren hastalıkların artması sonucu PCP, HIV negatif immünsupresif hastalarda daha yaygın hale gelmiştir. Bu çalışmada, Mersin Üniversitesi Hastanesinde yatan immün sistemi baskılanmış, semptomatik ve radyolojik olarak atipik pnömoni bulgusu olan hastalarda mikroskopi, polimeraz zincir reaksiyonu (PCR) ve Krebs von den Lungen-6 (KL-6) testleri ile PCP ve kolonizasyonlarının araştırılması amaçlanmıştır. ÇaIışmaya, Ağustos 2016-Şubat 2018 tarihleri arasında, \%75'i immünsupresif tedavi alan 96 hasta dahil edilmiştir. Hastalardan alınan solunum yolu örneklerinde [balgam $(n=88)$, trakeal aspirat $(n=6)$ ve bronkoalveoler lavaj $(n=2)$ ], mtLSU-rRNA nested-PCR ve mikroskobik boyama yöntemleri [immünfloresan testi "immunofluorescence assay (IFA)", "Toluidine Blue O (TBO)"] ile P.jirovecii araştırılmış ve serum örneklerinde KL-6 seviyesi test edilmiştir. Çalışmaya dahil edilen 96 hasta örneğinin 16 (\%16.7)'sında PCR, 5 (\%5.2)'inde IFA, 3 (\%3.1)'ünde ise TBO ile P.jirovecii tespit edilmiştir. IFA referans alındığında; TBO için duyarlılık \%60, özgüllük \%100; PCR için duyarlılı \%100, özgüllük \%87.9 olarak bulunmuştur. P.jirovecii PCR pozitif hastaların altta yatan hastalıklara göre dağıımı; kanser $(n=6)$, hematolojik malignite $(n=3)$, HIV/AIDS $(n=3), \operatorname{KOAH~}(n=2)$ ve interstisyel akciğer hastalığı $(n=2)$ şeklindedir. Pozitif 16 hastanın 11 (\%68.75)'i immünsupresif tedavi alan HIV pozitif non-Hodgkin lenfoma, 3 (\%18.75)'ü immünkompetan, 2 (\%12.5)'si ise yalnız HIV/AIDS tanısı olan hastalardan oluşmuştur. PCR pozitif 16 hastadan mikroskobik incelemesi de pozitif olan beşi, kesin PCP [HIV/AIDS $(n=3)$, akciğer kanseri $(n=1)$, interstisyel akciğer hastalığı $(n=1)$ ]; PCR pozitif, mikroskopisi negatif olan üç hasta olası PCP [multipl miyelom $(n=1)$, interstisyel akciğer hastalığı $(n=1)$, kolanjiyoselüler karsinom $(n=1)$ ] ve diğer sekiz hasta kolonize olarak 
tanımlanmıştır. Çalışmada, altta yatan hastalıklara göre P.jirovecii saptanma sıklığı ise sadece HIV/AIDS hastalarında istatistiksel olarak anlamlı derecede yüksek bulunmuştur $(p=0.012)$. KL-6, PCP/olası PCP ve kolonizasyon olarak tanımlanan hastalar arasında değerlendirildiğinde, duyarlıık \%62.5 ve özgüllük \%75 olarak saptanmıştır. Çalışma sonucunda, balgam örneklerinde P.jirovecii tespitinde nested-PCR yöntemi duyarlı ve başarılı bulunmuştur. KL-6 testi, PCR pozitif hastalarda kolonizasyon ve enfeksiyon ayrımında yeterli bulunmamışır. Elde edilen sonuçlar, yatan hastaların bağışıklık durumuna ve klinik özelliklerine göre $P C P^{\prime}$ nin ayırıcı tanı listesinde olması gerektiğini göstermiştir. Ayrıca bölgemizde ve ülkemizdeki P.jirovecii enfeksiyonlarını anlayabilmek için genotiplendirme ve anti-PCP ilaçlara karşı direnç ile ilişkili moleküler epidemiyolojik çalışmalara gereksinim duyulmaktadır.

Anahtar kelimeler: Pneumocystis jirovecii; Pneumocystis pnömonisi; kolonizasyon; nested-PCR; KL-6

\section{ABSTRACT}

Pneumocystis jirovecii is an atypical fungus that causes P.jirovecii pneumonia (PCP) in immunocompromised patients. Currently, while the incidence of AIDS-related PCP is decreasing, PCP has become more common in HIV-negative immunosuppressive patients as a result of increased diseases requiring immunosuppressive therapy. In this study, it was aimed to investigate PCP and colonizations by microscopy, polymerase chain reaction (PCR) and Krebs von den Lungen-6 (KL-6) tests in symptomatic immunosuppressive inpatients with the sign of radiologically atypical pneumonia in Mersin University Hospital. A total of 96 patients, between August 2016 and February 2018 were included in the study. Seventy two (75\%) of the 96 patients were under immunosuppressive therapy. P.jirovecii was investigated in the respiratory tract samples [sputum $(n=88)$, tracheal aspirate $(n=6)$ and bronchoalveolar lavage $(n=2)$ ] by mtLSUrRNA nested PCR and microscopic staining methods [immunofluorescence assay (IFA), Toluidine Blue $\mathrm{O}$ (TBO)], and KL-6 levels were tested in serum samples. P.jirovecii was detected in $16(16.7 \%)$ samples by PCR, in five (5.2\%) samples by IFA, in three (3.1\%) samples by TBO stain method. When IFA was taken as a reference test, sensitivity and specificity of TBO and PCR were calculated as $60 \%$ and $100 \% ; 100 \%$ and $87.9 \%$, respectively. In P.jirovecii PCR positive patients, the distribution of underlying diseases; cancer $(n=6)$, hematological malignancy $(n=3), \operatorname{HIV} / \operatorname{AIDS}(n=3), \operatorname{COPD}(n=2)$, and interstitial lung disease $(n=2)$ were found as $11(68.75 \%)$ of the 16 positive patients, received immunosuppressive therapy (HIV positive non-Hodgkin lymphoma); of the $3(18.75 \%)$ patients of were immunocompetent, and only 2 (12.5\%) were HIV/AIDS. Five of the 16 PCR positive the patients that have positive microscopic examination were definited PCP [HIV/AIDS $(n=3)$, lung cancer $(n=1)$, interstitial lung disease $(n=1)]$; three patients were PCR positive and microscopy negative probable PCP [multiple myeloma $(n=1)$, interstitial lung disease $(n=1)$, cholangiocellular carcinoma $(n=1)$ ] and eight other patients were identified as colonized. In the study, when the frequency of the detection of P.jirovecii was evaluated according to the underlying diseases, it was found statistically significantly higher only in HIV/AIDS patients $(p=0.012)$. When KL- 6 was evaluated among the patients defined as PCP/possible PCP and colonization, sensitivity and specificity were determined as $62.5 \%$ and $75 \%$, respectively. As a result, nested PCR method was found as sensitive and successful for the detection of P.jirovecii from sputum samples. KL-6 test was not found sufficient for the differentiation of colonization and the infection in PCR positive patients. The results obtained in the study showed that PCP should be on the differential diagnosis list according to the immune status and the clinical features of the inpatients. More researchs are required with more patients to achieve for detailed reliable results in these groups. In addition, molecular epidemiological studies related to genotyping and resistance against anti-PCP drugs are needed to understand P.jirovecii infections in our region and country.

Keywords: Pneumocystis jirovecii; Pneumocystis pneumonia; colonization; nested-PCR; KL-6

\section{Giriş}

Pneumocystis jirovecii, akciğer tropizmi gösteren ve immün sistemi baskılanmış hastalarda fırsatçı enfeksiyona neden olan atipik bir fungustur ${ }^{1}$. P.jirovecii pnömonisi (PCP), insan immün yetmezlik virüsü [Human Immunodeficiency Virus (HIV)] pozitif hastalarda 
yaygın olarak görülürken, profilaksi ve antiretroviral tedavi ile birlikte kazanılmış immün yetmezlik sendromu [acquired immune deficiency syndrome (AIDS)] ilişkili PCP insidansı büyük oranda azalmıştır ${ }^{1,2}$. Günümüzde, hematolojik maligniteler, solid organ tümörleri, organ transplantasyonu ve otoimmün hastalıkların artması ile bu hastalıklar için uygulanan immün sistemi baskılayıcı tedaviler (kemoterapi, kortikosteroid, antirejeksiyon), PCP'yi HIV negatif immünsupresif hastalarda daha yaygın hale getirmiştir ${ }^{3-5}$.

PCP, HIV negatif immünsupresif hastalarda akut başlangıçlıdır ve semptomlar daha progresiftir ${ }^{1,6}$. Bu yüzden hızıı tanı önemlidir. P.jirovecii kültürü yapılamadığı için mikroorganizmanın kist ve trofozoit formlarının solunum yolu örneklerinde mikroskobik olarak gösterilmesi PCP için standart tanı yöntemidir ${ }^{6}$. Bunun için Giemsa, "Toluidine blue $\mathrm{O}$ (TBO)", kalkoflor beyazı, Gomori metenamin gümüş ve monoklonal immünfloresan testi [immunofluorescence assay (IFA)] boyama yöntemleri kullanılmaktadır ${ }^{1,6,7}$. Bu yöntemler arasında IFA, kist ve trofozoit formları hedef aldığı için duyarlılığı konvansiyonel boyama yöntemlerinden daha yüksektir ${ }^{7}$. Klinik örneklerden P.jirovecii tespitinde moleküler yöntemlerin kullanılması tanı duyarlılığını artırmıştır 7,8 . Ancak, P.jirovecii aktif enfeksiyon ve taşıyıcılık (kolonizasyon) durumlarında polimeraz zincir reaksiyonu [polymerase chain reaction (PCR)] ile pozitif sonuç alınmaktadır ${ }^{7,8}$. Bu yüzden mikroskopinin negatif, PCR yöntemlerinin pozitif olduğu durumlarda, PCP ve kolonizasyon ayrımının klinik bulgularla birlikte yorumlanarak yapılması gerekir ${ }^{8}$.

P.jirovecii PCR testinin pozitif ve mikroskopinin negatif olduğu durumlarda enfeksiyonkolonizasyon ayrımı için serum testleri tanıya yardımcı olarak kullanılabilir. Krebs von den Lungen-6 (KL-6) antijeni, tip 2 alveoler pnömosit ve bronşiyal epitel hücrelerden eksprese edilen bir glikoproteindir 9,10 . Interstisyel pnömonilerde ve akciğer hasarında salgılanarak serumda artış gösterir ${ }^{10}$. PCP'li hastalarda da artış gösterdiği bildirilmiştir ${ }^{9,11,12}$.

Bu çalışmada, Mersin Üniversitesi Hastanesinde yatan immün sistemi baskılanmış, semptomatik ve radyolojik olarak atipik pnömoni bulgusu olan hastalarda mikroskopi, PCR ve KL-6 yöntemleri ile PCP ve kolonizasyonlarının araştırılması amaçlanmıştır.

\section{GEREÇ ve YÖNTEM}

Bu çalışma, Mersin Üniversitesi Klinik Araştırmalar Etik Kurulu tarafından etik kurul onayı alınarak gerçekleştirildi (Tarih: 09.06.2016 ve Karar no: 2016/177).

Çalışmaya, Ağustos 2016-Şubat 2018 tarihleri arasında Mersin Üniversitesi Hastanesinin çeşitli servis ve yoğun bakım ünitelerinde takip edilen; klinik ve radyolojik bulgularına göre dispne, nonprodüktif öksürük, ateş, interstisyel pnömoni şikayetleriyle atipik pnömoni tespit edilen 96 hasta örneği dahil edildi. Hastalardan alınan serum ve alt solunum yolu örnekleri [balgam $(n=88)$, trakeal aspirat $(T A)(n=6)$ ve bronkoalveoler lavaj (BAL) $(n=2)]$, rutin test işlemleri yapıldıktan sonra çalışmada kullanılmak üzere saklandı.

Mukoid yapıda olan solunum yolu örnekleri, distile su ile hazırlanan $\% 0.3$ konsantrasyonunda "1,4-dithiothreitol (DTT)" ile muamele edilerek homojenize hale getirildi. İşlem sonunda konsantre olan örnekler, mikrosantrifüj tüplerinde $-20^{\circ} \mathrm{C}^{\prime}$ de saklandı. 


\section{Mikroskobik İnceleme}

Solunum yolu örneklerinden üçer adet preparat hazırlanarak havada kurutuldu. P.jirovecii trofozoit formlarının görüntülenmesi için Giemsa (Merck, Almanya) ile boyandı. P.jirovecii kist formlarının incelenmesi için ise modifiye TBO (Sigma-Aldrich, ABD) boyama yöntemi uygulandı ${ }^{13}$. Preparatlar, ışık mikroskobu ile $40 x$ ve $100 x$ objektifte incelendi. TBO boyama yöntemi, P.jirovecii kist formlarını boyayarak lavanta renginde görünüm sağlamaktadır. Preparatta tomurcuk oluşturmayan, lavanta renginde, biçimsiz, bal peteği benzeri küme oluşturan yapılar pozitif olarak değerlendirildi.

P.jirovecii kist ve trofozoit formlarının tespiti için ayrıca monoklonal bir IFA olan "Pneumo Cel Indirect IF Test" (Cellabs, Avustralya) kiti kullanıldı ve üretici firma önerilerine göre uygulandı. Preparatlar floresan mikroskop (530 nm dalga boyu) ile incelendi. İki ya da daha fazla kist (elma yeşili floresans) görülmesi pozitif olarak değerlendirildi.

\section{"Enzyme Linked Immunosorbent Assay" Testi}

Serum örneklerinden KL-6 tespiti için "Human KL-6 Enzyme Linked Immunosorbent Assay (ELISA) Kit (SunRed, Çin) (Test aralığı: 5-1.500 U/ml) kullanıldı ve çalışma, üretici firma önerileri doğrultusunda gerçekleştirildi.

\section{Pneumocystis jirovecii Polimeraz Zincir Reaksiyonu Yöntemi}

DNA izolasyonu, QIAamp DNA Blood Mini Kit (Qiagen, Almanya) ile kan ve vücut sıvılarından DNA izolasyon protokolü uygulanarak yapıldı.

Çalışmada, P.jirovecii tespiti için mtLSU rRNA gen bölgesini hedefleyen nested-PCR yöntemi uygulandı. Birinci tur PCR için pAZ102-E (5'-GAT GGC TGT TTC CAA GCC CA-3') ve pAZ102-H (5'-GTG TAC GTT GCA AAG TAC TC-3'); ikinci tur PCR için pAZ102-X (5'-GTG AAA TAC AAA TCG GAC TAG G-3') ve PAZ102-Y (5'-TCA CTT AAT ATT AAT TGG GGA GC-

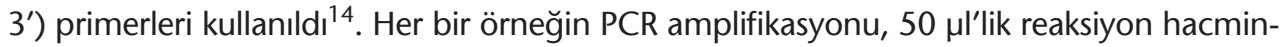
de gerçekleştirildi. Birinci tur için PCR reaksiyon karışımı; $5 \mu \mathrm{l} 10$ x PCR tampon, $2 \mu \mathrm{mol} / \mu \mathrm{l}$ $\mathrm{MgCl}_{2}, 0.2 \mu \mathrm{mol} / \mu \mathrm{l} \mathrm{dNTP}$ karışımı, $0.25 \mathrm{pmol} / \mu \mathrm{l}$ her bir primer, $1.25 \mathrm{U}$ Taq DNA polimeraz ve $8 \mu$ örnek DNA'sı içermektedir. İkinci tur PCR bileşenleri benzer şekilde hazırlandı ve birinci tur PCR ürününden $3 \mu l^{\prime} l i k$ örnek, kalıp DNA olarak kullanıldı. Örneklerin amplifikasyon koşulları, birinci tur için $94^{\circ} \mathrm{C}^{\prime}$ de 5 dakika başlangıç denatürasyonu, ardından 40 döngü $94^{\circ} \mathrm{C}^{\prime}$ de 1 dakika denatürasyon, $55^{\circ} \mathrm{C}^{\prime}$ de 1 dakika bağlanma ve $72^{\circ} \mathrm{C}^{\prime}$ de 1.5 dakika uzama basamakları ve son olarak $70^{\circ} \mathrm{C}^{\prime}$ de 5 dakika son uzama basamağı şeklinde uygulandı. İkinci tur amplifikasyon için ise primer bağlanma sıcaklığı $50^{\circ} \mathrm{C}$ olacak şekilde aynı termal döngü koşulları kullanıldı. Amplifikasyon ürünleri, $0.5 \mu \mathrm{g} / \mathrm{ml}$ etidyum bromür içeren $\% 1$ 'lik agaroz jelde 120 voltta 40 dakika elektroforeze tabi tutulduktan sonra ultraviole ışığı altında görüntülendi. Birinci ve ikinci tur PCR ürünlerinden sırasıyla 346 ve 263 baz çifti (bp) uzunluğunda bant elde edilen örnekler pozitif olarak değerlendirildi ${ }^{14}$.

\section{Pneumocystis jirovecii Pnömonisi ve Kolonizasyon Sınıflandırması}

P.jirovecii tespit edilen hastalarda klinik sınıflandırma, daha önce araştırmacılar tarafından kullanılan kriterlere göre yapıldı ${ }^{15,16}$. 
Kesin Pneumocystis jirovecii pnömonisi: Dispne, öksürük, ateş gibi tipik kliniğin ilerleyici şekilde seyretmesi ve radyolojik bulguların buzlu cam opasiteleri ya da infiltrasyon şeklinde olması, mikroskopinin pozitifliği, anti-PCP tedavisi ile enfeksiyonun çözülmesi.

Olası Pneumocystis jirovecii pnömonisi: Uyumlu klinik ve radyolojik bulguları olan hastalarda PCR'nin pozitif, mikroskopinin negatif olması, anti-PCP tedavisi ile enfeksiyonun çözülmesi.

Kolonizasyon: PCR'nin pozitif, mikroskopinin negatif olduğu durumlarda atipik klinik ve radyolojik bulguların olması, antibiyotik tedavisi ile semptomların çözülmesi.

\section{İstatistiksel Analiz}

Sürekli değişkenler, normal dağılım varsayımı sağlandığı durumda ortalama (değişim aralığı), sağlanmadığı durumda ise medyan (min-maks) şeklinde özetlendi. Kategorik değişkenler, sayı ve yüzde cinsinden özetlendi. Sürekli bir değişken bakımından iki grup arasında fark olup olmadığını incelemek için Mann-Whitney $U$ testinden yararlanıldı. Oranlar arasındaki farklııklar için iki oran z testinden yararlanıldı. KL-6 parametresinin grupları ayırmadaki başarısını değerlendirmek için ROC analizinden yararlanıldı. i̇statistiksel anlamlılık düzeyi olarak $\mathrm{p}<0.05$ kabul edildi.

\section{BULGULAR}

Çalışmaya dahil edilen 96 hastanın 64 (\%67)'ü erkek, 32 (\%33)'si kadın olup, yaş ortalaması $60 \pm 14.6$ (min-maks: 18-90) yıl olarak belirlenmiştir. Hastaların 79 (\%82.3)'unu serviste, 17 (\%17.7)'sini ise yoğun bakım ünitesinde yatanlar oluşturmuştur. Hastalardan alınan solunum yolu örneklerinin 88 (\%91.6)'i balgam, $6(\% 6.3)^{\prime}$ sı trakeal aspirat ve 2 (\%2.1)'si BAL olarak belirlenmiştir.

Hastaların 39 (\%40.62)'unun solid organ tümörü, 27 (\%28.12)'sinin hematolojik maligniteler, 5 (\%5.20)'inin organ transplantasyonu, 4 (\%4.16)'ünün HIV/AIDS, 3 (\%3.13)'ünün otoimmün hastalıklar, 12 (\%12.50)'sinin КОAН, 3 (\%3.13)'ünün interstisyel akciğer hastalığı, 18 (\%18.75)'inin ise diğer hastalıklar nedeni ile tedavi gördüğü belirlenmiştir (Tablo I).

Çalışmadaki 96 hastanın 72 (\%75)'si immünsupresif tedavi almış ve bunların 44'ü sadece kemoterapi, 15'i sadece steroid, sekizi kemoterapi ve steroid, beşi antirejeksiyon tedavisi alan hastalardan oluşmuştur.

Çalışmadaki 96 hasta örneğinin 16 (\%16.7)'sında PCR, 5 (\%5.2)'inde IFA, 3 (\%3.1)'ünde TBO ve 2 (\%2.1)'sinde Giemsa yöntemi ile P.jirovecii tespit edilmiştir (Resim 1, Tablo II). PCR ve mikroskobik inceleme yöntemlerinin sonuçları uyumlu bulunmuştur.

P.jirovecii tespit edilen 16 hastanın 11 (\%69)'i erkek, 5 (\%31)'i kadın olup, yaş ortalaması $61 \pm 12$ (min-maks: 40-82) yıl olarak belirlenmiştir. PCR pozitif hastaların altta yatan hastalıklara göre dağılımı; altı kanser, üç hematolojik malignite, üç HIV/AIDS, iki KOAH ve iki interstisyel akciğer hastalığı olarak belirlenmiştir (Tablo I). Pozitif 16 hastanın 11 (\%68.75)'i immünsupresif tedavi alan (biri HIV pozitif non-Hodgkin lenfoma), 3 (\%18.75)'ü immünkompetan ve diğer 2 (\%12.5)'si yalnızca HIV/AIDS olarak tespit edilmiştir. 


\begin{tabular}{|lcc|}
\hline Tablo I. Hastaların Altta Yatan Hastalık Gruplarına Göre Dağııımı & \\
\hline Altta yatan hastalıklar & $\begin{array}{c}\text { Toplam hasta sayısı } \\
\mathbf{n}=\mathbf{9 6}(\%)\end{array}$ & $\begin{array}{c}\text { P.jirovecii pozitif hasta sayısı } \\
\mathbf{n}=\mathbf{1 6}(\%)\end{array}$ \\
\hline Hematolojik maligniteler & $27(28.12)$ & $3(18.75)$ \\
Lösemi & $15(15.62)$ & - \\
Lenfoma & $4(4.17)$ & $2(12.5)$ \\
Multipl miyelom & $6(6.25)$ & $1(6.25)$ \\
Miyelodisplastik sendrom & $2(2.08)$ & - \\
Solid tümörler & $39(40.62)$ & $6(37.5)$ \\
Akciğer kanseri & $22(22.91)$ & $4(25.0)$ \\
Diğer kanserler & $17(17.71)$ & $2(12.5)$ \\
Organ nakli & $5(5.20)$ & - \\
Böbrek nakli & $5(5.20)$ & - \\
HIV/AıIDS & $4(4.16)$ & $3(18.75)$ \\
Otoimmün hastalıklar & $3(3.13)$ & - \\
Romatoid artrit & $2(2.08)$ & - \\
Ankilozan spondilit & $1(1.04)$ & - \\
Diğer hastalıklar & $18(18.75)$ & $4(25.0)$ \\
KOAH & $12(12.50)$ & $2(12.5)$ \\
Interstisyel akciğer hastalığı & $3(3.13)$ & $2(12.5)$ \\
Kronik böbrek yetmezliği, DM & $2(2.08)$ & - \\
Kronik kalp yetmezliği, DM & $1(1.04)$ & - \\
\hline HIV: Insan immün yetmezlik virüsü, AIDS: Kazanılmış immün yetmezlik sendromu, KOAH: Kronik obstrüktif \\
akciğer hastalığı.
\end{tabular}

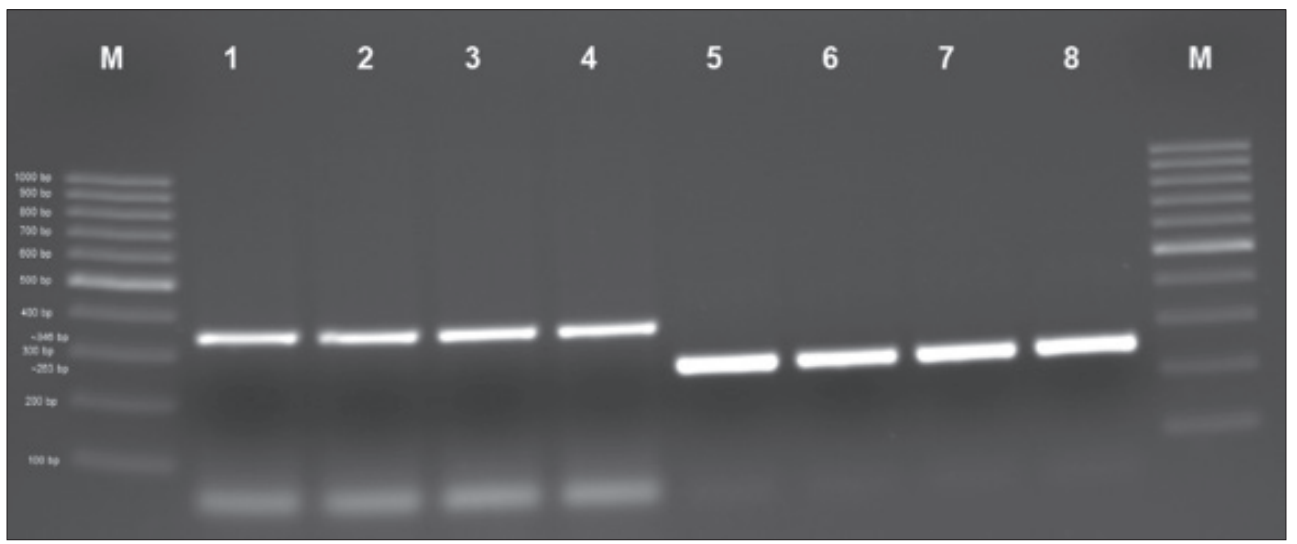

Resim 1. P.jirovecii mtLSU nested-PCR agaroz jel elektroforez görüntüsü; Kolon M: Moleküler ağırlık belirteci (GeneRuler 100 bp Plus DNA Ladder, Thermo Scientific); Kolon 1-4: Birinci tur PCR ürünleri (346 bp) ve Kolon 5-8: ikinci tur PCR ürünleri (263 bp). 


\begin{tabular}{|c|c|c|c|c|c|}
\hline Hasta no & PCR & IFA & TВO & Giemsa & Klinik değerlendirme \\
\hline 2 & Pozitif & - & - & - & Kolonizasyon \\
\hline 6 & Pozitif & - & - & - & Kolonizasyon \\
\hline 8 & Pozitif & Pozitif & - & - & PCP \\
\hline 20 & Pozitif & - & - & - & Kolonizasyon \\
\hline 28 & Pozitif & - & - & - & Olası PCP \\
\hline 32 & Pozitif & - & - & - & Kolonizasyon \\
\hline 56 & Pozitif & Pozitif & - & - & PCP \\
\hline 60 & Pozitif & Pozitif & Pozitif & - & PCP \\
\hline 62 & Pozitif & - & - & - & Olası PCP \\
\hline 68 & Pozitif & - & - & - & Kolonizasyon \\
\hline 70 & Pozitif & - & - & - & Kolonizasyon \\
\hline 73 & Pozitif & Pozitif & Pozitif & Pozitif & PCP \\
\hline 85 & Pozitif & - & - & - & Kolonizasyon \\
\hline 86 & Pozitif & - & - & - & Olası PCP \\
\hline 90 & Pozitif & - & - & - & Kolonizasyon \\
\hline 98 & Pozitif & Pozitif & Pozitif & Pozitif & PCP \\
\hline
\end{tabular}

IFA ile pozitif bulunan beş hastanın tamamı erkek ve yaş ortalaması $61 \pm 9$ (min-maks: 45-70) yıl olup, bu hastaların üçünde HIV/AIDS, birinde akciğer kanseri ve birinde interstisyel akciğer hastalığı tanısı gözlenmiştir.

IFA yöntemi referans alındığında: Giemsa için duyarlıık \%40 (\%95 güven aralığı (GA): 6.49-84.60), özgüllük \%100 (\%95 GA: 95.99-100); TBO için duyarlılı \%60 (\%95 GA: 15.40-93.51), özgüllük \%100 (\%95 GA: 95.99-100); PCR için duyarlılık \%100 (\%95 GA: 47.95-100), özgüllük \%87.9 (\%95 GA: 79.40-93.80) olarak hesaplanmıştır.

PCR ile P.jirovecii saptanan 16 hastadan IFA sonucu da pozitif olan beş hasta kesin PCP [HIV/AIDS ( $n=3)$, akciğer kanseri $(n=1)$, interstisyel akciğer hastalığı $(n=1)$ ]; PCR pozitif, IFA negatif üç hasta, olası PCP [multipl miyelom $(n=1)$, interstisyel akciğer hastalığı $(n=$ $1)$, kolanjiyoselüler karsinom $(n=1)$ ] ve diğer sekiz hasta kolonize olarak değerlendirilmiştir (Tablo II). P.jirovecii tespit edilen hastaların bilgileri ise Tablo III'te görülmektedir.

Çalışmada, altta yatan hastalıklara göre P.jirovecii saptanma sıklığı ise sadece HIV/AIDS hastalarında istatistiksel olarak anlamlı derecede yüksek bulunmuştur $(p=0.012)$ (Tablo IV). Çalışmaya dahil edilen HIV/AIDS pozitif dört hastanın üçünde IFA ve PCR ile P.jirovecii saptanmış olup, kliniği ile değerlendirildiğinde kesin PCP olarak tanımlanmıştır.

Serum KL-6 seviyesi, PCP/olası PCP ve kolonizasyon olarak tanımlanan hastalar arasında değerlendirildiğinde, kesim noktası > 500 alındığında; duyarlılık \%62.5 (\%95 GA: 24.791.0) ve özgüllük \%75 (\%95 GA: 35.0-96.1) olarak tespit edilmiştir (Şekil 1). 


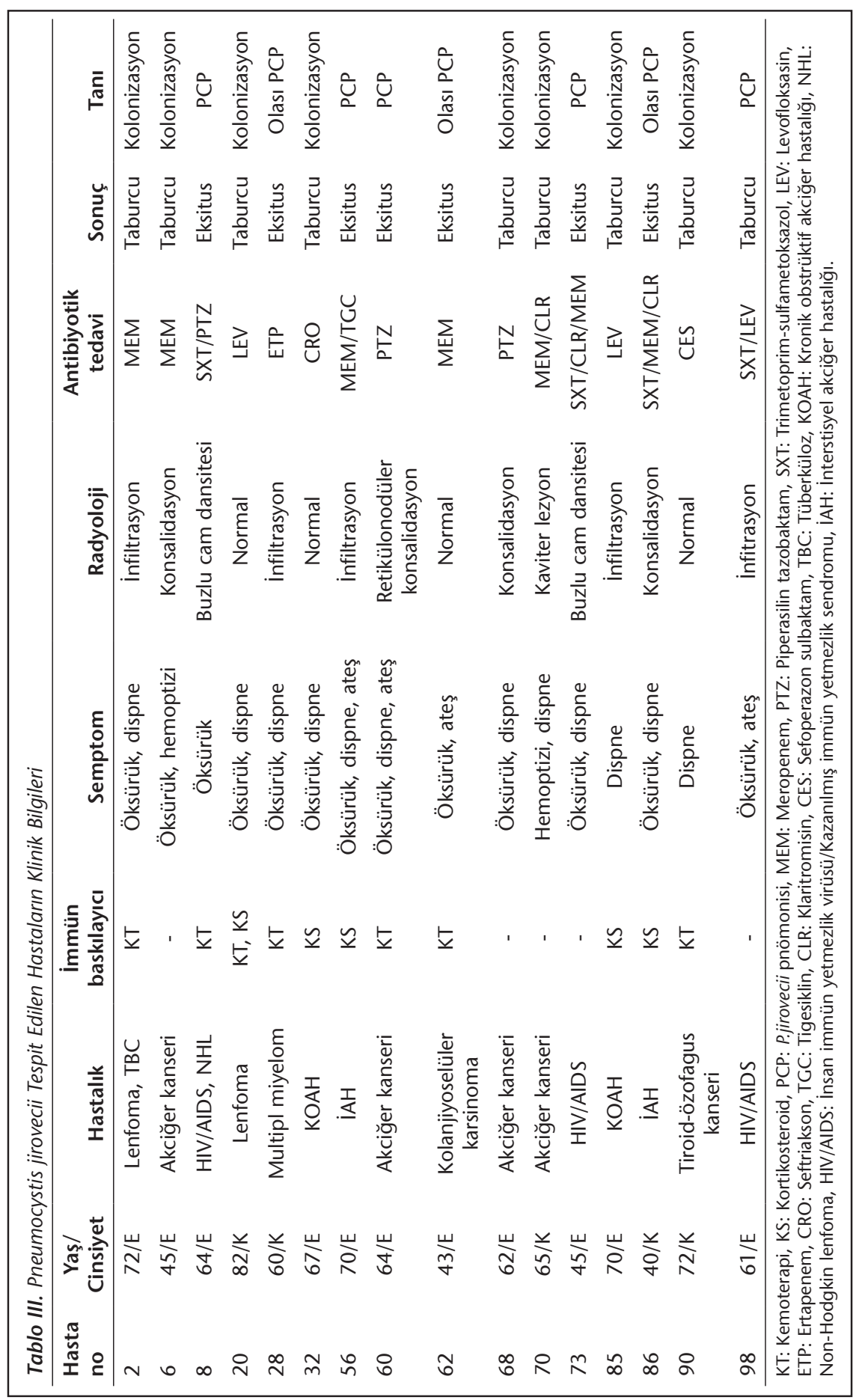




\begin{tabular}{|lcccc|}
\hline \multicolumn{4}{|c}{ Tablo IV. Hastaların Klinik ve Demografik Özellikleri } & \multicolumn{3}{c|}{$\begin{array}{c}\text { P.jirovecii pozitif } \\
\mathbf{n}=\mathbf{1 6}(\%)\end{array}$} & $\begin{array}{c}\text { P.jirovecii negatif } \\
\mathbf{n}=\mathbf{8 0}(\%)\end{array}$ & $\mathbf{p}$ \\
\hline Yaş ortalaması (yıl) & $61(40-82)$ & $60(18-90)$ & 0.743 \\
Cinsiyet, erkek & $11(69)$ & $53(66)$ & 0.846 \\
Hematolojik maligniteler & $3(18.75)$ & $24(30.0)$ & 0.542 \\
Solid tümörler & $6(37.5)$ & $33(41.25)$ & 1.000 \\
Organ nakli & - & $5(6.25)$ & - \\
HIV/AIDS & $3(18.75)$ & $1(1.25)$ & $0.012^{*}$ \\
Otoimmün hastalıklar & - & $3(3.75)$ & - \\
KOAH & $2(12.5)$ & $10(12.5)$ & 0.678 \\
İnterstisyel akciğer hastalığı & $2(12.5)$ & $1(1.25)$ & 0.115 \\
Diğer hastalıklar & - & $3(3.75)$ & - \\
İmmünsupresif tedavi & $11(68.75)$ & $61(76.25)$ & 0.752 \\
$\quad$ Sadece kemoterapi & $6(37.5)$ & $38(47.5)$ & 0.647 \\
Antirejeksiyon & - & $5(6.25)$ & - \\
Sadece steroid & $4(25.0)$ & $11(13.75)$ & 0.451 \\
Kemoterapi ve steroid & $1(6.25)$ & $7(8.75)$ & 0.869 \\
Mikrobiyoloji kültüründe üreme & $8(50.0)$ & $29(36.25)$ & 0.453 \\
Trimetropim-sulfametoksazol tedavi veya profilaksi & $4(25.0)$ & $18(22.5)$ & 0.913 \\
\hline * P<0.05 & & & \\
\hline
\end{tabular}

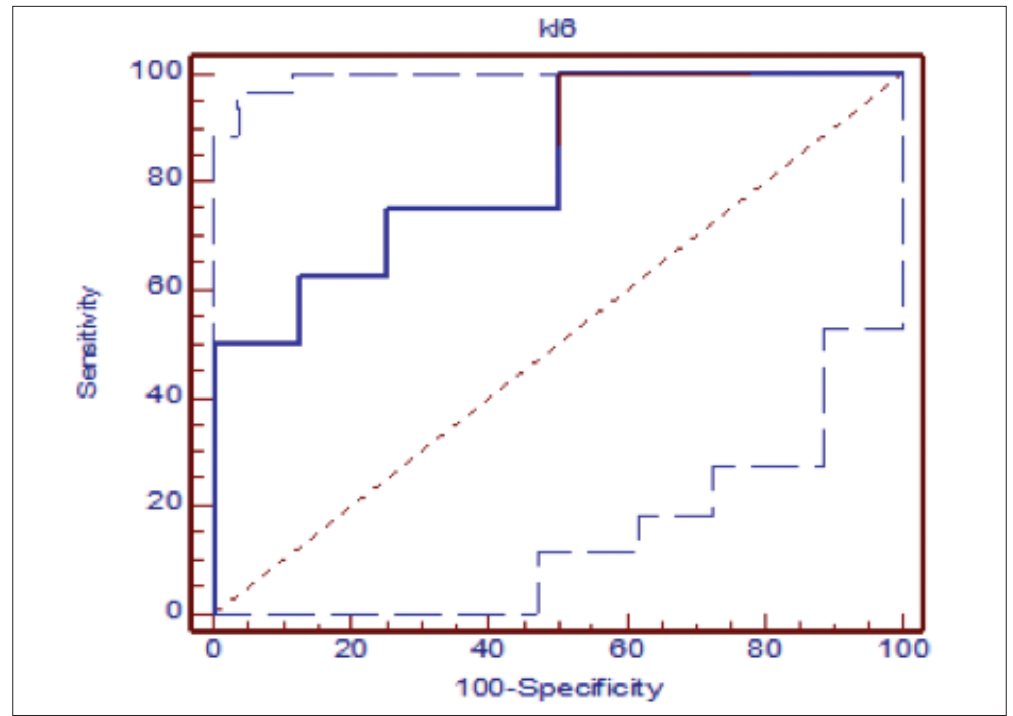

Şekil 1. Serum KL-6 seviyesinin PCP ve kolonizasyon olarak tanımlanan örnekler arasındaki değerlendirmesi; kesim noktası > 500 alındığında duyarlılık \%62.5 (\%95 Cl; 24.7-91.0) ve özgüllük \%75 (\%95 GA: 35.0-96.1). 


\section{TARTIŞMA}

Global verilere göre, yıllık yaklaşık 500.000 P.jirovecii olgusu görüldüğü tahmin edilmektedir. Her 100.000 'de en fazla olgunun Nijerya $(n=48.2)$, Kenya $(n=43)$ ve Tanzanya $(n=22)^{\prime}$ da; en az olgunun Danimarka $(n=0.04)$, Bangladeş $(n=0.04)$ ve Macaristan $(n=$ $0.1)^{\prime}$ da görüldüğü bildirilmiştir ${ }^{17}$. Tüm P.jirovecii olgularının \%77'si Afrika, \%10'u Amerika Birleşik Devletleri, \%7'si Avrupa, \%6'sı ise Asya'dan bildirilmiştir ${ }^{17}$.

Ülkemizden P.jirovecii'nin araştırıldığı çalışmalarda, çeşitli hasta gruplarında \%8-38 arasında P.jirovecii pozitifliği bildirilmiştir ${ }^{16,18-23}$. Töz ve arkadaşları, gerçek zamanlı PCR yöntemi ile PCP şüphesi olan 42 hastadan alınan BAL örneklerinin \%38 (16/42)'inde; Özkoç ve arkadaşları, nested-PCR ile immün sistemi baskılanmış hastalardan alınan BAL örneklerinin \%33.7 (31/92)'sinde; Tekinşen ve arkadaşları ise gerçek zamanlı PCR ile immünsupresif 100 hastanın \%8'inde P.jirovecii pozitifliği bildirmişlerdir ${ }^{16,22,23}$. Çalışmamızda, \%75'inde immün sistemi baskılanmış olan 96 hastanın 16 (\%16.7)'sında P.jirovecii pozitifliği tespit edilmiştir. Bu oran, ülkemizden bildirilen değerler arasındadır.

PCP tanısında P.jirovecii kist ve trofozoit formlarının solunum yolu örneklerinde mikroskobik olarak gösterilmesi standart tanı yöntemidir ${ }^{6}$. Solunum yolu örneklerinden indüklenmiş balgam örneği ile \%50-90 oranında tanı konulabilirken; BAL örneğinde bu oran \%90-98' dir $^{1,24}$. IFA mikroskopi yönteminin duyarlılık ve özgüllüğü diğer boyama yöntemlerinden daha yüksektir ${ }^{25,26}$. Ancak, HIV negatif immünsupresif hastalarda akciğer P.jirovecii yükünün düşük olması mikroskobik tanının duyarlılığını azaltmaktadır ${ }^{27}$. Klinik örneklerden P.jirovecii tespitinde PCR yöntemlerinin kullanılması tanı duyarılı̆̆ını artırmıştır. Özellikle mtLSU rRNA nested-PCR kullanılması, mikroskopinin negatif olduğu düşük parazit yükü bulunan hastalarda tanının sağlanmasında etkilidir ${ }^{8,15}$. Aderaye ve arkadaşları, TBO, IFA ve PCR yöntemlerini karşılaştırdıkları çalışmada, 131 hastanın 56 (\%42.7)'sında PCR, 39 (\%29.4)'unda IFA ve 28 (\%21.4)'inde TBO yöntemi ile pozitiflik tespit etmişlerdir ${ }^{28}$. Aynı çalışmada, TBO boyama IFA ve PCR ile karşılaştırıldığında, balgam örneklerinde sırasıyla duyarlılık \%71.4 ve \%34.5; BAL örneklerinde ise duyarlılı \%68 ve \%41.5 olarak bildirilmiştir $^{28}$. Çalışmamızda, 96 hasta örneğinin 16 (\%16.7)'sında PCR, beşinde (\%5.2) IFA, üçünde (\%3.1) TBO ve ikisinde (\%2.1) Giemsa yöntemi ile P.jirovecii tespit edilmiştir. Hastaların balgam örneklerinde önemli oranda P.jirovecii saptanmış olması, hastanemizde ve bölgemizde daha fazla PCP olabileceğini düşündürmüştür.

Çalışmamızda IFA yöntemi referans alındığında: Giemsa boyama yöntemi ile duyarlılık ve özgüllük sırasıyla \%40 ve \%100; TBO yöntemi ile \%60 ve \%100; PCR ile \%100 ve \%87.9 olarak bulunmuştur. Nested-PCR yönteminin duyarlıığının yüksek olmasından dolayı PCR'nin pozitif, mikroskopinin negatif olduğu sonuçlar PCR yönteminin özgüllüğünü düşürmüştür. Bu tip sonuçlarda kolonizasyon ve enfeksiyon ayrımı yapmak için PCR sonuçları klinik bulgularla birlikte değerlendirilmelidir. Çalışmamızda, PCR ve IFA yönteminin pozitif olduğu beş hasta kesin PCP; PCR pozitif, mikroskopi negatif üç hasta olası PCP ve diğer sekiz hasta kolonize olarak değerlendirilmiştir. PCP tespit edilen beş hastadan HIV/ AIDS tanısı olan üç hasta anti-PCP tedavisi almış olup, biri iyileşerek taburcu edilmiş, diğer 
dört hasta ise hastanede yattıkları süreçte kaybedilmiştir. Olası PCP olarak tanımlanan üç hastadan biri anti-PCP tedavisi almış, ancak üç hasta da kaybedilmiştir. Bu sonuçlar, HIV negatif immünsupresif hastalarda PCP'nin önemli bir sıklığa sahip olduğunu ve mikroskopinin negatif olduğu durumlarda PCR sonuçlarının tedaviye karar vermede etkili olabileceğini göstermiştir.

HIV negatif immünkompetan bireylerde P.jirovecii kolonizasyonunu gösteren çalışmalar olmasına rağmen immün sistemi baskılayıcı tedavi alan (kortikosteroid ve/veya kemoterapötik ajanlar) hastalarda kolonizasyonun daha fazla saptandığı görülmüştür ${ }^{4,29}$. İmmünsupresif hastalarda P.jirovecii'nin en fazla bildirildiği hastalıklar sırasıyla; hematolojik maligniteler, solid organ tümörleri, otoimmün hastalıklar, kronik akciğer hastalıkları ve organ transplant alıcılarıdır ${ }^{3-5}$. Çalışmamızda, altta yatan hastalıklara göre P.jirovecii saptanma sıklığı, sadece HIV/AIDS hastalarında istatistiksel olarak anlamlı derecede yüksek bulunmuştur $(p=0.012)$. Çalışmaya dahil edilen HIV/AIDS pozitif dört hastanın üçünde PCP saptanmıştır. Bu sonuç, HIV/AIDS pozitif hastalarda P.jirovecii'nin önemli bir etken olmaya devam ettiğini göstermektedir. Bunun nedeninin, HIV pozitif hastaların antiretroviral tedavi rejimine düzenli uymaması ya da uygulanan profilaksiye bağlı olarak P.jirovecii izolatlarının anti-PCP ilaçlara karşı direnç geliştirmiş olabileceği düşünülmüştür. Diğer yandan, bu şekildeki profilaksi ve tedavi başarısızıı̆ı, hastaların P.jirovecii pozitif kalmasına neden olabilecektir.

Son yıllara ait çalışmalarda HIV/AIDS pozitif hastalarda PCP'nin azalma eğiliminde olduğu gösterilmesine rağmen Dünya Sağlık Örgütü HIV/AIDS 2018 Sürveyans Verileri'ne göre Avrupa Birliği ülkelerinde, PCP (\%21), AIDS'e bağlı en yaygın görülen enfeksiyon olarak bildirilmiştir ${ }^{4,5,30}$.

KL-6, interstisyel akciğer hastalıklarında ve akut akciğer yaralanmalarında serumda artış gösteren bir indikatördür ve $P C P^{\prime} l i$ hastalarda da serumda anlamlı olarak yüksek bildirilmiştir ${ }^{9,11,12}$. Çok merkezli bir çalışmada, KL-6 seviyesi PCP'li hastalarda PCP negatif hastalara göre anlamlı olarak daha yüksek tespit edilmiş ve KL-6 için duyarlılık \%71.5 ve özgüllük ise \%78.8 olarak bildirilmiştir ${ }^{12}$. Başka bir çalışmada, serum KL-6 seviyesi HIV pozitif PCP'li hastalarda HIV negatif PCP'li ve diğer akciğer enfeksiyonlarından anlamlı olarak daha yüksek tespit edilmiş, ancak HIV negatif PCP'li hastalar ile diğer akciğer hastalığı olanlar arasında anlamlı bir fark bulunmamıştır ${ }^{11}$. Çalışmamızda P.jirovecii tespit edilen hastalar arasında KL6'nın PCP ve kolonizasyon ayrımındaki etkinliği değerlendirildiğinde, duyarılık \%62.5 ve özgüllük \%75 bulunmuştur. Bazı çalışmalarda, KL-6'nın PCP ve kolonizasyon ayrımında başarılı bulunmadığı görülmüştür ${ }^{10,12}$. Çalışmamızda ise PCR pozitif örneklerde kolonizasyon ve PCP ayrımında serum KL-6 seviyesinin rutin kullanımda yeterli olmadığı belirlenmiştir.

Çalışmamızın en önemli kısıtılığı, ağırıklı olarak balgam örnekleri ile çalışılmış olması ve PCP tanısı için mikroskobik boyama yöntemlerinde sitosantrifüj uygulamasının yapılmamış olmasıdır.

Sonuç olarak, bu çalışmada bölgemizdeki P.jirovecii epidemiyolojisi hakkında önemli veriler elde edilmiştir. Balgam örneklerinden P.jirovecii tespitinde nested-PCR yöntemi duyarlı 
ve başarılı bulunmuştur. KL-6 testi, PCR pozitif hastalarda kolonizasyon ve enfeksiyon ayrımında yeterli bulunmamıştır. Çalışmada elde edilen sonuçlar, yatan hastaların bağışıklık durumuna ve klinik özelliklerine göre PCP'nin ayırıcı tanı listesinde olması gerektiğini göstermiştir. Bu gruplarda daha güvenilir sonuçlara ulaşmak için daha fazla sayıda hastanın yer aldığı çalışmaların planlanması gerekmektedir. Ayrıca bölgemiz ve ülkemizdeki P.jirovecii enfeksiyonlarını anlayabilmek için genotiplendirme ve anti-PCP ilaçlarına karşı direnç ile ilişkili moleküler epidemiyolojik çalışmalara gereksinim duyulmaktadır.

\section{ETIK KURUL ONAYI}

Bu çalışma, Mersin Üniversitesi Klinik Araştırmalar Etik Kurulu tarafından etik kurul onayı alınarak gerçekleştirildi (Tarih: 09.06.2016 ve Karar no: 2016/177).

\section{TEŞEKKÜR}

Bu çalışmada istatistiksel analizin yapılmasına yardımcı olan Mersin Üniversitesi Biyoistatistik ve Tıbbi Bilişim Anabilim Dalı Öğretim Üyesi Dr. Didem Derici Yıldııım’a teşekkür ederim.

\section{ÇIKAR ÇATIŞMASI}

Yazarlar bu makale ile ilgili herhangi bir çıkar çatışması bildirmemişlerdir.

\section{KAYNAKLAR}

1. Calderon EJ, Varela JM, Durand-Joly I, Dei-Cas E. Pneumocystis jirovecii pneumonia, pp: 1-36. In: Saurez ML, Ortega SM (ed), Pneumonia: Symptoms, Diagnosis and Treatment. 2011, Nova Science Publishers Inc, NY, USA.

2. Kelley CF, Checkley W, Mannino DM, Franco-Paredes C, Del Rio C, Holguin F. Trends in hospitalizations for AIDS-associated Pneumocystis jirovecii pneumonia in the United States (1986 to 2005). Chest 2009; 136(1): 190-7.

3. Liu Y, Su L, Jiang SJ, Qu H. Risk factors for mortality from Pneumocystis carinii pneumonia (PCP) in non-HIV patients: a meta-analysis. Oncotarget 2017; 8(35): 59729-39.

4. Bienvenu AL, Traore K, Plekhanova I, Bouchrik M, Bossard C, Picot S. Pneumocystis pneumonia suspected cases in 604 non-HIV and HIV patients. Int J Infect Dis 2016; 46: 11-7.

5. Pereira-Díaz E, Moreno-Verdejo F, de la Horra C, Guerrero JA, Calderón EJ, Medrano FJ. Changing trends in the epidemiology and risk factors of Pneumocystis pneumonia in Spain. Front Public Health 2019; 7: 275.

6. Sokulska M, Kicia M, Wesołowska M, Hendrich AB. Pneumocystis jirovecii-from a commensal to pathogen: Clinical and diagnostic review. Parasitol Res 2015; 114(10): 3577-85.

7. Alanio A, Hauser PM, Lagrou K, Melchers WJ, Helweg-Larsen J, Matos O, et al. ECIL guidelines for the diagnosis of Pneumocystis jirovecii pneumonia in patients with haematological malignancies and stem cell transplant recipients. J Antimicrob Chemother 2016; 71(9): 2386-96.

8. Fan LC, Lu HW, Cheng KB, Li HP, Xu JF. Evaluation of PCR in bronchoalveolar lavage fluid for diagnosis of Pneumocystis jirovecii pneumonia: A bivariate meta-analysis and systematic review. PLoS One 2013; 8(9): e73099.

9. Tasaka S, Hasegawa N, Kobayashi S, Yamada W, Nishimura T, Takeuchi T, et al. Serum indicators for the diagnosis of Pneumocystis pneumonia. Chest 2007; 131(4): 1173-80.

10. Shimizu Y, Sunaga N, Dobashi K, Fueki M, Fueki N, Makino S, et al. Serum markers in interstitial pneumonia with and without Pneumocystis jirovecii colonization: A prospective study. BMC Infect Dis 2009; 9: 47. 
11. Nakamura H, Tateyama M, Tasato D, Haranaga S, Yara S, Higa F, et al. Clinical utility of serum beta-D-glucan and KL-6 levels in Pneumocystis jirovecii pneumonia. Intern Med 2009; 48(4): 195-202.

12. Esteves F, Calé SS, Badura R, de Boer MG, Maltez F, Calderón EJ, et al. Diagnosis of Pneumocystis pneumonia: Evaluation of four serologic biomarkers. Clin Microbiol Infect 2015; 21(4): 379.e1-10.

13. Gosey LL, Howard RM, Witebsky FG, Ognibene FP, Wu TC, Gill V], et al. Advantages of a modified toluidine blue $\mathrm{O}$ stain and bronchoalveolar lavage for the diagnosis of Pneumocystis carinii pneumonia. J Clin Microbiol 1985; 22(5): 803-7.

14. Tamburrini E, Mencarini P, Visconti E, Zolfo M, De Luca A, Siracusano A, et al. Detection of Pneumocystis carinii DNA in blood by PCR is not of value for diagnosis of P.carinii pneumonia. J Clin Microbiol 1996; 34(6): 1586-8.

15. Maillet M, Maubon D, Brion JP, François P, Molina L, Stahl JP, et al. Pneumocystis jirovecii (Pj) quantitative PCR to differentiate Pj pneumonia from Pj colonization in immunocompromised patients. Eur J Clin Microbiol Infect Dis 2014; 33(3): 331-6.

16. Özkoç S, Bayram Delibaş S. Investigation of Pneumocystis jirovecii pneumonia and colonization in iatrogenically immunosuppressed and immunocompetent patients. Mikrobiyol Bul 2015; 49(2): 221-30.

17. Bongomin F, Gago S, Oladele RO, Denning DW. Global and multi-national prevalence of fungal diseasesestimate precision. J Fungi (Basel) 2017; 3(4): 57.

18. Güneş I, Kalkanci A, Kuştimur S, Ergüven S, Ozet G, Ekim N. Comparison of the methenamine silver staining, direct fluorescent antibody and nested-polymerase chain reaction methods in the diagnosis of Pneumocystis carinii pneumonia. Mikrobiyol Bul 2004; 38(1-2): 105-12.

19. Döşkaya M, Caner A, Değirmenci A, Wengenack NL, Yolasığmaz A, Turgay N, et al. Degree and frequency of inhibition in a routine real-time PCR detecting Pneumocystis jirovecii for the diagnosis of Pneumocystis pneumonia in Turkey. J Med Microbiol 2011; 60(Pt 7): 937-44.

20. Özmen A, Mıstık R, Alver O, Coşkun F, Ursavaş A, Uzaslan E. The Pneumocystis jirovecii colonization in bronchoalveolar lavage (BAL) and bronchial washing and the comparison of methods which are used in diagnosis. Tuberk Toraks 2013; 61(4): 303-11.

21. Tosun I, Buruk K, Dede R, Kaklıkaya N. Investigation of Pneumocystis jirovecii in respiratory samples of immunocompromised patients with PCR, IFA and Giemsa staining methods. Mikrobiyol Bul 2013; 47(1): 195-7.

22. Tekinşen FF, Koç AN. Investigation of Pneumocystis jirovecii in clinical specimens by different methods. Mikrobiyol Bul 2013; 47(4): 658-67.

23. Töz S, Gündüz C, Tetik A, Taşbakan M, Pullukçu H, Bacakoğlu F, et al. The comparison of microscopy and real time polymerase chain reaction methods for the diagnosis of Pneumocystis jirovecii pneumonia: evaluation of clinical parameters. Tuberk Toraks 2017; 65(3): 220-6.

24. Lu JJ, Lee CH. Pneumocystis pneumonia. J Formos Med Assoc 2008; 107(11): 830-42.

25. Cruciani M, Marcati P, Malena M, Bosco O, Serpelloni G, Mengoli C. Meta-analysis of diagnostic procedures for Pneumocystis carinii pneumonia in HIV-1-infected patients. Eur Respir J 2002; 20(4): 982-9.

26. Procop GW, Haddad S, Quinn J, Wilson ML, Henshaw NG, Reller LB, et al. Detection of Pneumocystis jirovecii in respiratory specimens by four staining methods. J Clin Microbiol 2004; 42(7): 3333-5.

27. Monnet X, Vidal-Petiot E, Osman D, Hamzaoui O, Durrbach A, Goujard C, et al. Critical care management and outcome of severe Pneumocystis pneumonia in patients with and without HIV infection. Crit Care 2008; 12(1): R28.

28. Aderaye G, Woldeamanuel Y, Asrat D, Lebbad M, Beser J, Worku A, et al. Evaluation of toluidine blue O staining for the diagnosis of Pneumocystis jirovecii in expectorated sputum sample and bronchoalveolar lavage from HIV-infected patients in a tertiary care referral center in Ethiopia. Infection 2008; 36(3): 237-43.

29. Qoraan I, Oz Y, Metintas M, Durmaz G. The investigation of Pneumocystis jirovecii colonization in adult individuals of Turkish population. Biom Biostat Int J 2018; 7(4): 311-5.

30. World Health Organization (WHO). HIV/AIDS surveillance in Europe 2018. World Health Organization, 2018. 